\title{
AS FORMAS DE EXPRESSÃO DA MODALIDADE VOLITIVA NOS DISCURSOS DO PAPA FRANCISCO EM VIAGEM APOSTÓLICA ${ }^{1}$ THE FORMS OF EXPRESSION OF THE VOLITIVE MODALITY
IN POPE FRANCISCO'S SPEECHES ON APOSTOLIC JOURNEY
}

\author{
André Silva Oliveira ${ }^{2}$ \\ Nadja Paulino Pessoa Prata ${ }^{3}$
}

\begin{abstract}
RESUMO
Este artigo apresenta uma descrição e análise das formas de expressão usadas para a instauração da modalidade volitiva em língua espanhola com base nos discursos do Papa Francisco em viagem apostólica, tendo em vista a proposta tipológica da categoria modalidade apresentada na Gramática Discursivo-Funcional (GDF) e os diversos estudos sobre essa categoria em língua espanhola (SEDANO, 2006; GARCÍA, 2009; TOPOR, 2011; GARCÍA, 2013; e OLIVEIRA, 2017). Os resultados revelam que as construções volitivas foram as mais empregadas $(34,2 \%)$, seguida pelos usos de verbo pleno $(29,1 \%)$ e auxiliar modal (24,8\%). O emprego majoritário das construções volitivas se dá em virtude do modo subjuntivo, que é o modo verbal prototípico para a instauração das modalizações volitivas, relacionadas à manifestação da desejabilidade de potencialização de algum evento volitivo, geralmente, em relação a algo do qual o Sumo Pontífice não teria controle. Constatamos também o uso das orações finais com a estruturação "para...+para que+subjuntivo" para a expressão da modalidade volitiva, em que há uma vinculação de um dado estado-de-coisas, que é expresso com base em uma intenção (volição), com prospectividade futura, de caracterização hipotética para expressar um desejo pessoal do Sumo Pontífice.
\end{abstract}

PALAVRAS-CHAVES: Gramática Discursivo-Funcional; Modalidade Volitiva; Formas de Expressão.

\begin{abstract}
This article presents a description and analysis of the forms of expression used for the introduction of the volitive modality in the Spanish language based on the discourses of Pope Francis on apostolic journey, considering the typological proposal of the modality category presented in the Functional Discourse Grammar (FDG) and the various studies on this category in the Spanish language (SEDANO, 2006, GARCÍA, 2009, TOPOR, 2011, GARCÍA, 2013 and OLIVEIRA, 2017). The results show that the volitive constructs were the most used (34.2\%), followed by the use of verb of full meaning $(29.1 \%)$ and modal auxiliary (24.8\%). The majority use of volitive constructions is due to the subjunctive mode, which is the prototypical verbal mode for the instauration of the volitive modality related to the manifestation of the desirability of potentiating some volitive event, generally, in relation to something of which the Supreme Pontiff does not would have

${ }^{1}$ Cf. Oliveira (2017), para uma visão mais ampla das formas de expressão da modalidade volitiva. Este trabalho faz parte da dissertação de mestrado defendida no ano de 2017, intitulada: A modalidade volitiva em língua espanhola nos discursos do Papa Francisco em viagem apostólica.

2 Doutorando em Linguística pelo Programa de Pós-Graduação em Linguística da Universidade Federal do Ceará (PPGL/UFC). Integra o Grupo de Pesquisa em Funcionalismo (GEF), atuando na linha de descrição e análise da língua espanhola sob o viés da perspectiva funcionalista. E-mail: andrethtzn@gmail.com

3 Doutora em Linguística. Professora do Departamento de Letras Estrangeiras da Universidade Federal do Ceará (DLE/UFC). Professora do Programa de Pós-Graduação em Linguística (PPGL/UFC). Vice-líder do Grupo de Pesquisa em Funcionalismo (GEF/UFC). E-mail: nadja.prata@gmail.com
\end{abstract}


control. We also note the use of the final clauses with the structuring "para...+para que+subjuntivo" for the expression of the volitive modality, in which there is a binding of a given State-of-Affairs, which is expressed on the basis of an intention (volition), with future prospectivity, hypothetical characterization and to express a personal desire of the Supreme Pontiff.

KEYWORDS: Functional Discourse Grammar; Volitive Modality; Forms of Expression.

\section{INTRODUÇÃO}

A categoria da modalidade constitui um recurso linguístico pelo qual o falante expressa, ao ouvinte, a sua subjetividade em relação a um estado-de-coisas (EC). Por isso, o falante busca utilizar a expressão linguística adequada, levando em consideração a informação pragmática do ouvinte, para fazer-se entender ao manifestar suas opiniões, crenças ou desejos. Para tal finalidade, o falante pode fazer uso de modalizadores (expressões linguísticas) que "sinalizem" os reais objetivos de seu discurso.

A Gramática Discursivo-Funcional (doravante, GDF), de Hengeveld e Mackenzie (2008), com base em dois parâmetros, estabelece uma tipologia das modalidades: (i) o alvo da avaliação, que diz respeito à parte do enunciado que é modalizada; e (ii) o domínio semântico, que remete à perspectiva pela qual a avaliação modal é feita. No que diz respeito ao alvo da avaliação, as modalidades podem ser: (i) orientadas-para-o-participante, que corresponde à relação entre um dado participante (ou as propriedades referentes a ele) e um evento e a realização potencial desse evento por ele; (ii) orientadas-para-o-evento, diz respeito à descrição do evento que está presente no enunciado, sendo por isso a parte descritiva do enunciado; e (iii) orientadas-para-a-proposição, que faz referência à parte do enunciado por meio da qual o falante manifesta as suas visões e crenças, especificando, necessariamente, o seu grau de comprometimento com a sua proposição apresentada no enunciado. Por sua vez, em relação ao domínio semântico, a modalidade pode ser de cinco tipos: (i) facultativa, que está relacionada com as habilidades intrínsecas do falante; (ii) deôntica, que se refere às avaliações morais; (iii) epistêmica, relacionada ao conhecimento sobre o mundo real; (iv) evidencial, que tem relação com a fonte da informação; e (v) volitiva, relacionada à expressão dos desejos, foco deste estudo.

A modalidade volitiva, conforme esses autores, refere-se ao que é (in)desejável, por isso está relacionada à manifestação da volição, que pode ser codificada, em língua espanhola, de diferentes formas, o que nos levou a identificar as estruturas morfossintáticas das quais o falante se utiliza para 'traduzir' a desejabilidade, que é fruto de uma necessidade que lhe é interna (OLBERTZ, 2016). Para este trabalho, focalizamos no que já é previsto, segundo Sedano (2006), García (2009), Topor (2011) e García (2013), em língua espanhola, para a manifestação da volição, e no que é proposto por Oliveira (2017), ${ }^{4}$ a saber: (i) auxiliares modais, como no exemplo: Me quiero hacer prójimo [Quero me fazer próximo] (OLIVEIRA, 2017, p. 117); (ii) verbos plenos, por exemplo: Queremos seguridad, demos seguridad [Queremos segurança, demos segurança] (OLIVEIRA, 2017, p. 117); (iii) construções volitivas com verbo suporte, para exemplificar: Hago votos para que este acuerdo sea duradero [Faço votos para que este acordo seja duradouro] (OLIVEIRA, 2017, p. 183); (iv) substantivos volitivos, como neste exemplo: El Papa cultivaba desde hace tiempo el deseo de mirarla [O Papa cultivava há algum tempo o desejo de olhá-la] (OLIVEIRA, 2017, p. 182); (v) adjetivos em função predicativa, para dar um exemplo: Es necesario buscar no el alimento que perece, sino el que perdura para la vida eterna [É necessário buscar não o alimento que perece, mas aquele que perdura para a vida eterna] (OLIVEIRA, 2017, p. 180); e (vi) orações finais

${ }^{4}$ As traduções dos exemplos foram retiradas de Oliveira (2017). 
(para... para+que+subjuntivo), como por exemplo: En estos días tendré ocasión de ir al Cobre, como bijo y como peregrino, para pedirle a nuestra Madre por todos sus bijos cubanos y por esta querida Nación, para que transite por los caminos de justicia, paz, libertad y reconciliación [Nestes dias terei a ocasião de ir ao Cobre, como filho e como peregrino, para pedir a Nossa Mãe por todos os seus filhos cubanos e por esta querida Nação, para que transite pelos caminhos de justiça, paz, liberdade e reconciliação] (OLIVEIRA, 2017, p. 232).

Em um primeiro momento, apresentaremos algumas definições acerca de como a modalidade pode expressar-se nas línguas, discorrendo sobre o Nível Morfossintático, que é o responsável pelos aspectos estruturais da expressão linguística, tomando também por escopo a codificação das diferenças interpessoais (Nível Interpessoal) e representacionais (Nivel Representacional), com base na Gramática Discursivo-Funcional (GDF), de Hengeveld e Mackenzie (2008). Em seguida, discorremos sobre a delimitação e constituição do corpus, que se compõe dos discursos religiosos proferidos pelo Papa Francisco, em língua espanhola, durante as suas viagens apostólicas realizadas aos Estados Unidos (país de forte concentração hispânica), a Cuba, ao México, ao Equador, a Bolívia e ao Paraguai. Apresentamos alguns apontamentos no que diz respeito ao discurso religioso católico, que, segundo Martins e Cordelia (2015), trata-se de um gênero argumentativo no qual a autoridade religiosa católica procura influenciar a forma de agir dos fiéis, comunicando-lhes os desejos, vontades ou intenções daquilo que a divindade ou a Igreja Católica espera em relação às questões de fé, moral, conduta, etc... Em um terceiro momento, descreveremos e analisamos as formas de expressão da modalidade volitiva em língua espanhola com base em Oliveira (2017), procurando observar a função que as manifestações da volição exercem na organização discursiva dos discursos religiosos do Santo Padre; e, por último, os resultados e as reflexões obtidas.

\section{As formas de expressão da modalidade volitiva}

Na teoria da GDF, de Hengeveld e Mackenzie (2008), a marcação morfossintática das expressões linguísticas de uma dada língua se dá no Nível Morfossintático (doravante $\mathrm{NM}$ ), nível que é o responsável pelos aspectos estruturais da unidade linguística, juntamente com o Nível Fonológico (doravante NF), que também se ocupa da codificação das diferenças interpessoais e representacionais, níveis do âmbito da Formulação. Dessa forma, muito do que ocorre no NM é funcionalmente motivado por princípios ordenadores referentes à iconicidade, à integridade de domínio e à manutenção das relações de escopo. Ao mesmo tempo, o NM possui seus próprios princípios de organização, como, por exemplo, a imposição arbitrária de um padrão de ordem de constituinte básico que, em si mesmo, não pode ser considerado funcionalmente motivado. A GDF não faz distinção entre um nível de análise sintático e outro morfológico, pois os princípios que são empregados na formação das palavras são os mesmos que operam na formação de frases e orações. Estruturalmente, o NM compõe-se das seguintes camadas: Expressão linguística $(\mathrm{Le})>$ Oração $(\mathrm{Cl})>\operatorname{Sintagma~}(\mathrm{Xp})>$ Palavra $(\mathrm{Xw})>$ Base $(\mathrm{Xs})>$ Afixo (Aff).

Tendo em vista a estruturação do NM, de acordo com Hengeveld e Mackenzie (2008), a camada mais alta do NM é a Expressão Linguística (Le), que se refere, necessariamente, a qualquer conjunto de pelo menos uma unidade morfossintática. Se ocorrer mais de uma unidade dentro da Expressão Linguística (Le), essas unidades terão as mesmas propriedades morfossintáticas. As unidades que se combinam para formar a Expressão Linguística (Le) são as Cláusulas (Cl), os Sintagmas (Xp) ou as Palavras (Xw). Conforme os autores, ao serem introduzidas as Expressões Linguísticas (Le) na análise linguística na GDF, foi possível tratar de diferentes frases e enunciados, fossem eles oracionais ou não. Em relação às unidades que compõem a Expressão Linguística (Le), a Cláusula $(\mathrm{Cl})$ refere-se a um conjunto de um ou mais Sintagmas (Xp) e, possivelmente, de 
Palavras (Xw), caracterizando-se por um esquema para a ordenação desses Sintagmas (Xp) e também por expressões morfológicas de conexão. Ainda segundo os autores, a Cláusula $(\mathrm{Cl})$ pode operar como um domínio para vários processos morfossintáticos, sendo que isso dependerá, necessariamente, de critérios específicos de cada língua. O Sintagma (Xp) apresenta como núcleo um tipo de "peça" léxica que advém do Nível Interpessoal (doravante NI) ou do Nível Representacional (doravante NR), sendo que não há, necessariamente, uma correspondência um a um entre as classes e lexemas identificados em uma língua e os tipos de Sintagmas (Xp) e classes de Palavras (Xw) correspondentes na mesma língua. A Palavra (Xw), por sua vez, pode ser muito complexa, podendo conter Temas (Xs) e Afixos (Aff), e também estratos superiores, como Sintagmas (Xp) e Cláusulas $(\mathrm{Cl})$.

A estruturação hierárquica disposta no NM, segundo Hengeveld e Mackenzie (2008), propicia a operação de Codificação que, por sua vez, é ancorada pelas representações semânticas que ocorrem no NR e pelas funções interpessoais no NI. Nesse sentido, as intenções comunicativas do falante, como a expressão de seus desejos (volição), são processadas nos níveis mais altos, NI e NR, influenciando, pois, na unidade linguística que será codificada no NM. Baseando-nos nisso, acreditamos que diferentes formas de expressão podem ser codificadas, em língua espanhola, para a manifestação da volição (valor modal referente à modalidade volitiva), o que, segundo Sedano (2006), García (2009), Topor (2011) e García (2013), pode ser instaurada por meio de: (i) formas ainda não gramaticalizadas na língua espanhola, sendo a volição expressa pelo falante caracterizada apenas pelo aspecto semântico dos verbos plenos ou léxicos, tais como querer, desear, necesitar, pretender, anhelar, ambicionar, lograr, etc.; (ii) construções linguísticas que expressem volição, tais como ojalá+infinitivo, que+subjuntivo, tener ganas, hacer votos, etc.; ou (iii) perífrases verbais já gramaticalizadas ${ }^{5}$ em espanhol como pensar+infinitivo, irta+infinitivo, baber +de+infinitivo, tratar + de + infinitivo, venir $+a+$ infinitivo, etc.

Resumidamente, podemos dizer que a modalidade volitiva e, consequentemente, a instauração do valor modal de volição, pode ser expressa em espanhol por meio de: (i) verbos de significação plena; (ii) construções volitivas; (iii) perífrases verbais; e (iv) verbos plenos com base no conteúdo semântico inferido pelo contexto. Além desses autores, Oliveira (2017) aponta algumas outras formas de expressão da modalidade volitiva, a saber: (v) adjetivos em função predicativa (es necesario, es deseable, es preferible, es importante, etc.); (vi) substantivos volitivos (deseo, intención, voluntad, anhelo, etc.); e (vii) orações finais (para...+para que + subjuntivo).

Sabendo que a modalidade volitiva está relacionada ao que é (in)desejável (HENGEVELD; MACKENZIE, 2008) e que pode ser codificada por diferentes formas de expressão em espanhol para a instauração do valor modal de volição, passemos agora para a constituição e delimitação do corpus e, posteriormente, para a descrição e análise das formas de expressão encontradas nos discursos do Papa Francisco.

\section{Metodologia}

Para que pudéssemos descrever a analisar as formas de expressão da modalidade volitiva em língua espanhola, optamos pelos discursos religiosos proferidos pelo Papa Francisco em quatro viagens apostólicas, realizadas pelo Sumo Pontífice entre os anos de 2015 e 2016 a países que tinham o espanhol como língua oficial, como Cuba, México, Equador, Bolívia e Paraguai e de forte concentração de nativos de língua espanhola, como

\footnotetext{
5 Segundo Topor (2011), apenas para a manifestação das “intenções", poderíamos encontrar perífrases verbais já gramaticalizadas.
} 
os Estados Unidos, onde o Santo Padre proferiu seus discursos, em espanhol para os católicos residentes nesse país (em sua maioria, hispanofalantes).

Os discursos foram divididos em dois grupos, de acordo com o tipo de ambiente em que foram proferidos (OLIVEIRA, 2017), a saber: (i) discursos proferidos em ambiente político (DAP); e (ii) discursos proferidos em ambientes religiosos (DAR). ${ }^{6}$

Considerando o tipo de discurso que foi selecionado para a composição do corpus, acreditávamos que ele seria favorável à manifestação da modalidade volitiva, tendo em vista que o líder religioso (Papa Francisco) tenderia a apresentar aos seus ouvintes, no caso, a comunidade religiosa católica e/ou a sociedade civil, os seus desejos, vontades e intenções acerca daquilo que lhe parece bom e agradável para o homem e/ou sua relação com os demais. No que diz respeito à vivência em sociedade, pensamos que o Santo Padre poderia modalizar, volitivamente, em relação à forma de agir dos católicos, comunicando por meio deles os objetivos e as intencionalidades, explícitas ou implícitas, daquilo que a Igreja Católica espera dos católicos, conforme nos esclarecem Martins e Cordelia (2015). Para isso, o Sumo Pontífice faz uso de estratégias de construção de enunciados, como a modalização em seus enunciados, no intuito de influenciar e admoestar o agir dos fiéis, 'moldando-lhes' o pensamento ao modelo católico de cristandade. De acordo com as autoras, as estratégias discursivas, empregadas pelo Papa Francisco, são utilizadas com alguma intencionalidade (volição), por isso possuem estreita relação com estratégias discursivas persuasivas, ideológicas, de silenciamento, etc. Tais estratégias dizem respeito à linguagem enquanto discurso, envolvendo outros aspectos, tais como a interação dos sujeitos (o líder religioso e os fiéis católicos), o contexto no qual os discursos são proferidos, as condições de produção dos discursos, os meios de produção e o públicoalvo. Desse modo elas não são selecionadas por acaso, já que cada estratégia empregada possui uma função e sua escolha é definida justamente por sua função.

Baseando-nos nessas características, acreditávamos que os discursos religiosos pronunciados pelo Papa Francisco seriam propícios para a manifestação da modalidade volitiva, que se refere ao que é (in)desejável. Sabendo-se da composição do nosso corpus, passemos agora a descrição e análise das formas de expressão da modalidade volitiva em língua espanhola nos discursos do Papa Francisco em viagem apostólica.

\section{A expressão da modalidade volitiva em língua espanhola: um exercício de análise nos discursos do Papa Francisco}

Como vimos anteriormente, a modalidade volitiva pode expressar-se, em língua espanhola, por distintas formas de expressão. Dentre as formas de expressão pautadas para a expressão da modalidade volitiva, comprovamos que houve uma preferência pelo uso de construção volitiva, seguida pelo emprego de verbo pleno e de auxiliar modal. Vejamos a Tabela 1:

Tabela 1: Formas de expressão da modalidade volitiva nos discursos do Papa Francisco proferidos em língua espanhola

Forma de Expressão

${ }^{6}$ Cf. Oliveira (2017). Os discursos foram assim divididos considerando uma das categorias de análise que era referente ao Componente Contextual, o tipo de ambiente. 


\begin{tabular}{ccc}
\hline & No. & $\%$ \\
\hline Construção volitiva & 40 & 34,2 \\
Verbo pleno & 34 & 29,1 \\
Auxiliar modal & 29 & 24,8 \\
Substantivo & 9 & 7,7 \\
Adjetivo em função predicativa & 5 & 4,2 \\
Total & 117 & 100,0 \\
\hline
\end{tabular}

Fonte: Extraída de Oliveira (2017, p. 176)

Como vemos, pela Tabela 1, há uma preferência pelo uso de construções volitivas nos discursos do Papa Francisco. Segundo Jímenez (1999), as construções volitivas são empregadas, costumeiramente, acompanhadas pelo modo subjuntivo, que é o modo verbal prototípico da modalidade volitiva, recobrindo, pois, a ideia de virtualidade do evento volitivo, que é referente a um estado-de-coisas sobre o qual incide o valor modal de volição. Ainda conforme o autor, o uso do modo subjuntivo responde as intencionalidades do falante, já que as intenções de performatização do evento volitivo têm sua origem nas funções desiderativas da linguagem. Vejamos (1) e (2):

(1) Viendo con los ojos y con el corazón sus rostros de Pastores, quisiera saludar también a las Iglesias que amorosamente llevan sobre sus hombros... Que ningún miembro del Cuerpo de Cristo y de la nación americana se sienta excluido del abrazo del Papa (DAR-1)

[Vendo com os olhos e com o coração seus rostos de Pastores, desejaria saudar também as Igrejas que amorosamente conduzem sobre seus ombros... Que nenhum membro do Corpo de Cristo e da nação americana se sinta excluído do abraço do Papa]

(2) No pretendo decirles lo que hay que hacer, porque todos sabemos lo que el Señor nos pide... Que la bumanidad sepa que contar con el «sacramento de unidad» (Lumen Gentium, 1) es garantía de que su destino no es el abandono y la disgregación (DAR-1)

[Não pretendo dizer-lhes o que é preciso que se faça, porque todos nós sabemos o que o Senhor nos pede... Que a humanidade saiba contar com o "sacramento da unidade" (Lumen Gentium, 1) é garantia de que seu destino não é o abandono e a desagregação]

Em (1) e (2), constatamos que o Papa Francisco faz uso da construção volitiva que+subjuntivo, já gramaticalizada, em língua espanhola, para expressar a modalidade volitiva. Por meio destas construções, o falante expressa, para os bispos e sacerdotes católicos, a desejabilidade de que "nenhuma pessoa que faça parte da Igreja de Cristo e da nação americana se sinta excluída do abraço dele" e de que "a humanidade possa contar com o sacramento da unidade" (eventos volitivos). Segundo Grande e García (1995), a construção volitiva que+subjuntivo (em especial, quando empregada no presente do subjuntivo, já que pode aparecer com os outros tempos verbais do subjuntivo, como o pretérito perfeito composto), aparece em língua espanhola como uma estrutura autônoma de conteúdo semântico desiderativo, podendo referir-se a uma desejabilidade em relação ao presente ou ao futuro, como nos exemplos: Que você durma bem! ${ }^{\beta}$ ou Que você não se canse?. Os autores ainda ressalvam que a construção volitiva que+subjuntivo pode estar relacionadas às ilocuções que se organizam em torno da estrutura do "desejar"10 (desejos positivos), como

\footnotetext{
${ }^{7}$ Exemplo adaptado de Oliveira (2017, p. 174).

8 Tradução nossa. O original diz: “iQue duermas bien!” (GRANDE; GARCÍA, 1995, p. 306).

9 Tradução nossa. O original diz: “QQue no te canses!” (GRANDE; GARCÍA, 1995, p. 306).

10 Para Hengeveld e Mackenzie (2008), os enunciados desiderativos com significado positivo de desejo relacionam-se à ilocuções de tipo optativa.
} 
no exemplo: Que você tenha sorte prova; ${ }^{11}$ ou às ilocuções que façam referência a "maldizeres", ${ }^{12}$ como no exemplo: Que um raio parta você! !'.

Salvo a construção volitiva que+subjuntivo, pudemos também constatar o emprego de outros tipos de construções volitivas, tais como hacer votos (fazer votos) e tener ganas (ter vontade). Vejamos (3) e (4):

(3) Hago votos para que este acuerdo sea duradero y eficazy dé los frutos deseados con la colaboración de todas las partes implicadas" (DAP-3) ${ }^{14}$

[Faço votos para que este acordo seja duradouro e eficaz e que dê os frutos desejados com a colaboração de todas as partes envolvidas].

(4) "[... tengo un discurso preparado pero no tengo ganas de leerlo $(\mathrm{D} A \mathrm{R}-4)^{15}$

[Tenho um discurso preparado, mas não tenho vontade de lê-lo].

Em (3), o Papa Francisco expressa seu desejo de que o acordo sobre a questão nuclear produza os efeitos esperados com a colaboração dos governos envolvidos na realização desse acordo. Para isso, o Papa Francisco utiliza a construção volitiva hacer votos (fazer votos), ${ }^{16}$ que poderia ser parafraseada da seguinte forma: Quiero que este acuerdo sea duradero y eficaz, y que dé los frutos deseados con la colaboración de todas las partes implicadas; empregando um "verbo suporte", como hacer (fazer). Em (4), o Papa Francisco expressa a sua indesejabilidade de proferir o discurso que foi elaborado para ser dirigido aos seminaristas e aos religiosos. Ao instaurar a modalidade volitiva, nesse caso, o Papa Francisco prefere utilizar-se de uma construção volitiva já lexicalizada na língua espanhola, no caso, tener ganas (ter vontade), também com o uso de um "verbo suporte", como tener (ter).

Seguido das construções volitivas, temos uma maior frequência de verbos de significação plena para a instauração de modalidade volitiva nos discursos do Papa Francisco, pois, segundo Oliveira (2017), esta forma de expressão é mais assertiva em apresentar a carga semântica do modalizador volitivo empregado. Vejamos (5) e (6):

(5) [...] todos aquellos que anhelan soluciones urgentes y efectivas $(D A P-3)^{17}$

[... todos aqueles que desejam soluções urgentes e efetivas]

(6) El México que deseamos legar a las generaciones venideras $(D A P-5)^{18}$

[O México que desejamos deixar para as próximas gerações]

Em (5), temos que o Papa Francisco faz uso do verbo anhelar, conjugado na terceira pessoa do plural, para reportar a desejabilidade de "todos aqueles" (fonte da atitude

\footnotetext{
11 Tradução nossa. O original diz: “QQue tengas suerte en el examen!” (GRANDE; GARCÍA, 1995, p. 307).

12 Para Hengeveld e Mackenzie (2008), os enunciados desiderativos com significado negativo de desejo relacionam-se à ilocuções de tipo imprecativa.

13 Tradução nossa. O original diz: “QQue te parta un rayo!” (GRANDE; GARCÍA, 1995, p. 307).

${ }^{14}$ Exemplo adaptado de Oliveira (2017, p. 183).

15 Exemplo adaptado de Oliveira (2017, p. 183).

${ }^{16}$ Construção volitiva com "verbo suporte".

${ }^{17}$ Exemplo adaptado de Oliveira (2017, p. 159).

${ }^{18}$ Exemplo adaptado de Oliveira (2017, p. 54).
} 
volitiva) que desejam "soluções urgentes e efetivas" (evento volitivo). Em (6), o Papa Francisco emprega o verbo volitivo desear, na primeira pessoa do plural, para referir-se a um desejo de âmbito coletivo ao discursar para a sociedade mexicana, em que o Santo Padre reporta o que parece ser o desejo de todos aqueles que formam parte da sociedade mexicana, de "legar para as próximas gerações, um México melhor e com maiores oportunidades" (evento volitivo). De acordo com Elholm (2015), os verbos volitivos, como querer, desear, anhelar, pretender, etc., pertencem ao grupo de "indutores" de desejo, vontade e intenção, os quais expressam a volição em relação ao que tomam por escopo. Nesse sentido, segundo o autor, quando empregados no presente do indicativo, estes verbos volitivos situam a volição manifestada para o momento da enunciação, ainda que o estado-de-coisas esteja situado em um momento posterior, descrevendo o desejo de falante em relação a uma situação hipotética, futura ou o desejo de que se mantenha uma situação já existente, como nestes exemplos citados pelo autor: Você fala de como repartir a riqueza e en quero gerar mais riqueza $a^{19}$ ou Eu vou sempre a uma agência, não quero cometer erros nessas coisas. ${ }^{20}$

Constatamos que o verbo volitivo querer também foi empregado tanto em sua forma de significação plena quanto por meio da construção perifrástica (querer+infinitivo). Vejamos (7) e (8):

(7) [...] queremos seguridad, demos seguridad; queremos vida, demos vida; queremos oportunidades, brindemos oportunidades. (DAP-2) ${ }^{21}$

[Queremos segurança, demos segurança; queremos vida, demos vida; queremos oportunidades, brindemos oportunidades]

(8) [...] Y yo vengo como esos pastores que fueron a Belén. Me quiero hacer prójimo." $(\mathrm{D} A \mathrm{R}-5)^{22}$

[E eu venho como esses pastores que foram a Belém. Quero fazer-me próximo].

Em (7) e (8), constatamos que o Papa Francisco preferiu empregar, para a instauração da modalidade volitiva, o verbo volitivo querer, respectivamente, em sua forma plena e como construção perifrástica. Em (7), o Sumo Pontífice expressa uma desejabilidade de âmbito coletivo (o que pode ser deduzido pelo emprego do modalizador na primeira pessoa do plural, queremos), a respeito de uma necessidade volitiva em relação "à segurança, bem-estar e melhores oportunidades de desenvolvimento humano" (evento volitivo). Em (8), o Papa Francisco fala de sua intenção (o que fica evidenciado pelo emprego do modalizador volitivo na primeira pessoa do singular, quiero) de "estar mais próximo da Sagrada Família" (evento volitivo). Para isso, o Papa Francisco faz menção à tradição cristã do nascimento de Jesus Cristo na cidade de Belém e da visita dos pastores à gruta onde se encontrava a Sagrada Família.

Segundo Cruz (1995), a utilização do verbo volitivo querer em sua forma plena faz com que se expresse um desejo mais "rotundo" e "categórico", principalmente, quanto ele é empregado no presente do indicativo, o que acentua a desejabilidade em relação ao

\footnotetext{
19 Tradução nossa. O original diz: "Tú hablas de cómo repartir la riqueza y yo quiero crear más riqueza" (ELHOLM, 2015, p. 15).

20 Tradução nossa. O original diz: "Yo me voy a una gestoría siempre, que no me quiero equivocar en esas cosas" (ELHOLM, 2015, p. 16).

${ }^{21}$ Exemplo adaptado de Oliveira (2017, p. 177).

22 Exemplo adaptado de Oliveira (2017, p. 177).
} 
evento volitivo expresso no enunciado. $\mathrm{O}$ autor ainda ressalta que o presente do indicativo implica uma menor transigência na mudança de planos do falante, ou seja, da possibilidade de que aquilo que é desejado não se trate de algo apenas passageiro, explicitando a desejabilidade do evento volitivo. Para Ruano (1996), o verbo querer (assim como o verbo volitivo apetecer) é um dos verbos mais prototípicos para a expressão da volição, pois seu significado semântico abarca os desejos e as vontades do falante em realizar algo ou a desejabilidade de que algo se concretize. Conforme Oliveira, Batista e Prata (2018) o emprego de verbos plenos para a instauração do valor modal de volição, deve-se a carga semântica que possui esses verbos, o que atenua a desejabilidade do evento volitivo. ${ }^{23}$ Em relação à construção perifrástica com o modal querer, segundo Tapia (2013), ela pode estar relacionada tanto à questão da aspectualidade do verbo em indicar uma ação futura, fazendo que o modal querer perca suas propriedades semânticas volitivas (quando o querer não é desejar), como no exemplo: Parece que hoje quer nevar; ${ }^{24}$ ou que manifeste suas características semânticas volitivas (quando o querer é desejar), como no exemplo: Quero comer. $^{25}$

Pela Tabela 1, comprovamos que, além das construções volitivas e dos verbos de significação plena, o falante também faz uso de auxiliares modais, como aparecem em (9) e (10):

(9) No pretendo decirles lo que hay que hacer $(D A R-1)^{26}$

[No pretendo dizer-lhes o que é preciso fazer]

(10) Prefiero más bien realizar de nuevo ese esfuerzo - antiguo y siempre nuevo- de preguntarnos por los caminos a seguir (DAR-1 $)^{27}$

[Prefiro realizar este esforço mais uma vez - sempre novo - para nos perguntar sobre os caminhos a seguir]

Em (9) e (10), vemos que o Papa Francisco emprega dois auxiliares modais, pretender+infinitivo e preferir+infinitivo, para modalizar volitivamente acerca de suas desejabilidades pessoais (o que fica evidenciado pelo emprego da primeira pessoa do singular, pretendo e prefiero) no que diz respeito a que "as mulheres grávidas toquem em suas barrigas" e "realizar o esforço de perguntar aos fieis qual o caminho a percorrer" (eventos volitivos). Segundo Plucarová (2007) e Rodríguez (2012), as construções pensartinfinitivo, pretender+infinitivo e preferir+infinitivo já se encontram gramaticalizadas em língua espanhola; por isso os verbos que acompanham a forma no infinitivo funcionam como auxiliares modais, empregados para a instauração das intencionalidades do falante ou para emitir uma predição acerca da possível atuação de seu(s) ouvinte(s), como nos exemplos: "Se digo para ela que não faça juízo sobre a minha pessoa, é porque pretendo ajudá-la, pretendo sustentála" 28 ou "Prefere mudar de tema". ${ }^{29}$

\footnotetext{
23 Para Oliveira (2017), o evento volitivo se caracteriza pela incidência de um valor modal volitivo sobre um estado-de-coisas (Evento) ou sobre um conjunto de estados-de-coisas relacionados entre si (Episódio).

${ }^{24}$ Tradução nossa. O original diz: "Parece que quiere ponerse a nevar" (TAPIA, 2013, p. 236).

25 Tradução nossa. O original diz: “Quiero comer” (TAPIA, 2013, p. 236).

${ }^{26}$ Exemplo retirado de Oliveira (2017, p. 51).

${ }^{27}$ Exemplo adaptado de Oliveira (2017, p. 215).

28 Tradução nossa. O original diz: "Si le digo que se ponga juiciosa conmigo, es porque la voy a ayudar/pretendo ayudarla/tengo la intención de ayudarla, la voy a mantener/pretendo mantenerla/tengo la
} 
Não apenas as construções volitivas, os verbos de significação plena e os auxiliares modais foram usados para a instauração da modalidade volitiva em língua espanhola. Os substantivos (11 a 14) e o adjetivo em posição predicativa (15), ainda que em baixa frequência, também foram empregados pelo Papa Francisco para a construção de seus enunciados marcados volitivamente. Vejamos, primeiramente, os casos de modalização volitiva com os substantivos:

(11) [...] el gobierno mexicano puede contar con la colaboración de la Iglesia Católica, que ba acompañado la vida de esta Nación y que renueva su compromiso y voluntad de servicio a la gran causa del hombre (DAP-5).

[O governo mexicano pode contar com a colaboração da Igreja Católica, que tem acompanhado a vida desta Nação e que renova o seu compromisso e vontade de serviço a grande causa do homem]

(12) [...] en este continente, las miles de personas que se ven obligadas a viajar hacia el norte en búsqueda de una vida mejor para si y para sus seres queridos, en un anhelo de vida con mayores oportunidades. ¿Acaso no es lo que nosotros queremos para nuestros hijos? (DAP-2)

[Neste continente, as milhares de pessoas que se veem obrigadas a viajar para o norte em busca de uma vida melhor para si e para seus entes queridos, em um desejo de vida com maiores oportunidades. Acaso não é o que queremos para os nossos filhos?].

(13) Como bizo San Juan Diego, y lo bicieron las sucesivas generaciones de los bijos de la Guadalupana, también el Papa cultivaba desde hace tiempo el deseo de mirarla. Más aún, quería yo mismo ser alcanzado por su mirada materna. (DAR-3).

[Como fez São João Diego e o fizeram as sucessivas gerações dos filhos da Guadalupana, também o Papa cultivava há algum tempo o desejo de olhá-la. Mas ainda, queria eu mesmo ser alcançado pelo seu olhar maternal]

(14) No es mi intención trazar un programa o delinear una estrategia. No be venido para juagarles o para impartir lecciones. (DAR-1)

[Não é minha intenção traçar um programa ou delinear uma estratégia. Não vim para lhes julgar ou para lhes dar lições de moral... que lhes fale como um irmão entre irmãos]

Em (11), o Papa Francisco reporta a desejabilidade da Igreja Católica, por meio do substantivo voluntad (vontade), de continuar "servindo a grande causa da humanidade" (evento volitivo), sendo também atenuado pelo uso do verbo "renovar" no presente do indicativo (que se refere à disposição e à atualização do evento volitivo). Em (12), temos que o Papa Francisco faz uso do substantivo anbelo (anelo) que, em espanhol, se emprega quando se pretende atenuar aquilo que é desejado, para fazer referência à volição de todos os imigrantes que se dirigem aos Estados Unidos, que o fazem "em busca de melhores condições de vida" (evento volitivo). Em (13), notamos que o Papa Francisco emprega o substantivo deseo (desejo) para expressar um desejo seu de "contemplar a imagem de Nossa Senhora de Guadalupe" (evento volitivo). Em (14), o Sumo Pontífice emprega o substantivo intención (intenção) para se referir a uma indesejabilidade sua de apresentar qualquer tipo "plano" ou "estratégia" a respeito "da forma da atuação dos bispos e sacerdotes em suas paróquias ou comunidades em relação ao tratamento que deve ser dado

intención de mantenerla" (RODRÍGUEZ, 2012, p. 12). Segundo o autor, neste contexto, a perífrase ir $+a+$ infinitivo adquire o mesmo valor da construção tener intención de e da perífrase pretender+infinitivo.

${ }^{29}$ Tradução nossa. O original diz: "Prefiere cambiar de tema” (PLUCAROVÁ, 2007, p. 26). 
aos fiéis católicos" (evento volitivo). Segundo Casimiro (2007), os substantivos são uma das formas lexicais mais usuais para marcar os desejos e vontades do falante, em virtude da carga semântica que eles acarretam ao enunciado, já que podem ser empregados em construções como: "É meu desejo" ou "É minha vontade" (CASIMIRO, 2007, p. 25). Para Granvik (2017), os substantivos modais de volição, tais como deseo, anhelo, voluntad, etc., tem o seu valor volitivo atenuado quando são ancorados por verbos volitivos, tais como querer, desear e pretender.

Em (15), podemos ver o emprego do adjetivo em função predicativa. Podemos constatar que o Papa Francisco emprega o modalizador es necesario para se referir a desejabilidade de que a humanidade "busque pelo alimento espiritual que não perece, mas que perdura para a vida eterna" (evento volitivo):

(15) Pero que no falte sereno valor de confesar que es necesario buscar no «el alimento que perece, sino el que perdura para la vida eterna» (In 6,27). (DAR-1).

[Mas que não falte sereno valor para confessar que é necessário buscar não «o alimento que perece, mas aquele que perdura para a vida eterna» (In 6,27)]

Consideramos que, em (15), há um caso de modalização volitiva, em virtude da desejabilidade manifestada ter origem em uma "necessidade volitiva" (OLBERTZ, 2016), haja vista que a sociedade civil não estaria obrigada a "buscar" o "alimento que perdura para a vida eterna", crença que deriva na existência de algo ou alguém superior (uma divindade). Ao modalizar por meio de um adjetivo em função predicativa, não há como inferir que se faça uma avaliação acerca da desejabilidade expressa, pois o emprego do verbo ser na terceira pessoa do singular es indetermina o sujeito que "deseja". Segundo Alarcón Neve (2008), o fato de que os adjetivos em função predicativa estejam acompanhados do verbo "ser", faz com que eles sejam similares aos verbos, haja vista que seu emprego equivale ao uso de verbos em sua forma de particípio como modificadores do enunciado modalizado.

Além das formas de expressão descritas e analisadas para a instauração da modalidade volitiva, Oliveira (2017) propõe também as orações finais do tipo para...+para que +subjuntivo como forma de instaurar modalizações volitivas. De acordo com o autor, é necessário que os estados-de-coisas vinculados ao "para" e ao "para que+subjuntivo": (i) estejam vinculados entre si, em que um se realiza com a intenção de que o outro ocorra; (ii) estejam direcionados para o futuro; (iii) sejam hipotéticos (não assertivos); e (iii) sejam instaurados por um agente prototípico que atue com volição e intenção e que seja o sujeito da oração principal. Vejamos (16) e (17):

(16) "Les hablo como Obispo de Roma, llamado por Dios - siendo ya mayor- desde una tierra también americana, para custodiar la unidad de la Iglesia universal y para animar en la caridad el camino de todas las Iglesias particulares, para que progresen en el conocimiento, en la fe y en el amor a Cristo." (DAR-1)

[Falo-lhes como Bispo de Roma, chamado por Deus - sendo o mais velho - desde uma terra também americana, para zelar a unidade da Igreja universal e para animar na caridade o caminho de todas as Igrejas particulares, para que progressem no conhecimento, na fé e no amor a Cristo]. 
(17) 'En estos días tendré ocasión de ir al Cobre, como bijo y como peregrino, para pedirle a nuestra Madre por todos sus hijos cubanos y por esta querida Nación, para que transite por los caminos de justicia, paz, libertad y reconciliación." (DAP-4)

[Nestes dias terei a ocasião de ir ao Cobre, como filho e como peregrino, para pedir a Nossa Mãe por todos os seus filhos cubanos e por esta querida Nação, para que transite pelos caminhos de justiça, paz, liberdade e reconciliação].

Em (16), constatamos que o Papa Francisco (sujeito oculto) é tanto o sujeito da oração principal (o que fica evidenciado pelo emprego da primeira pessoa do singular, hablo) quanto o sujeito da primeira oração final (com o para), tendo como volição o estadode-coisas apresentado na terceira oração final (com o para que), que seria "o progresso no conhecimento, na fé e no amor a Cristo" (aquilo que é desejado e esperado da missão episcopal do Sumo Pontífice). As duas orações finais se mostram vinculadas, haja vista que o fato de "ser o representante de Jesus Cristo" traz por propósito "custodiar a Igreja Católica" e, a partir dessa finalidade, a desejabilidade de que "as igrejas particulares progridam na fé e no amor a Cristo" (prospectividade futura e hipotética).

Em (17), verificamos que o Sumo Pontífice é o sujeito da oração principal e da primeira oração final; manifestando a volição em relação ao segundo estado-de-coisas "para que transite por caminhos de justiça, paz, liberdade e reconciliação" (que se refere ao que é desejado). As duas orações finais também se mostram vinculadas, pois o fato de o Papa Francisco ir ao Santuário de Nossa Senhora do Cobre tem por finalidade "fazer preces e orações a Nossa Senhora do Cobre pelo povo cubano e a nação cubana", tendo em mente que o Papa Francisco deseja que "a nação cubana transite por caminhos de paz, justiça e prosperidade" (prospectividade futura e hipotética). De acordo com Oliveira (2017), os exemplos de orações finais podem ser entendidos como casos de modalização volitiva em relação ao que se modaliza por meio do para+que+subjuntivo, em razão de haver um vínculo entre os estados-de-coisas apresentados, direcionados para o futuro e caráter hipotético. Esses estados-de-coisas são expressos com base em uma "intenção", que é oriunda de um ser humano, sendo, portanto, capaz de volição.

\section{CONCLUSÃO}

Neste trabalho, descrevemos e analisamos as formas de expressão utilizadas pelo Papa Francisco para a instauração da modalidade volitiva nos seus discursos proferidos em língua espanhola. Vimos que o Nível Morfossintático, na GDF, é o encarregado da codificação morfossintática e o responsável pelos aspectos estruturais da unidade linguística, ocupando-se da codificação das diferenças relativas à inter-relação entre Falante e Ouvinte (interpessoais) e das representações semânticas (representacionais), em que o Falante pode empregar, ao modalizar, diferentes formas de expressão, tais como auxiliares modais, verbos de significação plena, auxiliares modais, substantivos, adjetivos em função predicativa, etc., como foi constatado no corpus.

Após a análise do nosso corpus, verificamos que as formas de expressão mais empregadas pelo Papa Francisco foram às construções volitivas (34,2\%), no caso, o emprego do que+subjuntivo, hacer votos e tener ganas; seguidas de verbo pleno $(29,1 \%)$, em sua maioria, os verbos querer e desear, e de auxiliar modal (24,8\%), em questão, as perífrases já gramaticalizadas, como pretender+infinitivo e preferir+infinitivo. Constatamos também que as modalizações volitivas podem ser codificadas por outras formas, tais como: (i) substantivos volitivos (deseo, anhelo, voluntad, intención, etc.), que apresentam o seu valor semântico volitivo atenuado quando ancorados com verbos volitivos ou pela própria carga semântica do substantivo que é empregado para expressar volição; (ii) adjetivos em posição predicativa 
(es necesario), que são empregados quando o falante não deseja fazer alguma avaliação acerca do evento volitivo manifestado; e (iii) orações finais com a estrutura para...para+que+subjuntivo, que apresentam os estado-de-coisas vinculados entre si, estando direcionados para o futuro e de caráter hipotético, em que a intenção (volição) manifestada é oriunda de um ser animado [+ humano], ser este capaz de volição.

\section{REFERÊNCIAS}

ALARCÓN NEVE, Luisa Josefina. Adjetivos en predicación dentro de textos narrativos utilizados en la escuela primaria mexicana. 2008. 405f. Tese (Doutorado em Filologia) Programa de Pós-Graduação em Língua Espanhola e Linguística Geral, Universidade Nacional de Educação, México. Disponível em: <http://bit.ly/2EoLuuU>. Acesso em: 12 fev. 2018.

CASIMIRO, Sérgio. Um estudo das modalidades deôntica e volitiva nos discursos do presidente Lula. 2007. 107 f. Dissertação (Mestrado em Estudos Linguísticos) - Programa de Pós-Graduação em Estudos Linguísticos, Universidade Estadual Paulista, São José do Rio Preto. Disponível em: <https://bit.ly/2M4K4tj>. Acesso em: 19 dez. 2018.

CRUZ, Nieves Mendizábal de la. La expresión del deseo, ruego y mandato en español: punto de vista onomasiológico. Revista Centro Virtual Cervantes, ASELE, Actas VI, 1995. Disponível em: <http://zip.net/bktDMl>. Acesso em: 11 fev. 2017.

ELHOLM. Tine. El subjuntivo y nuestra concepción de la realidad y la capacidad de influir en ella: una propuesta para la explicación del subjuntivo dependiente aplicada a un debate político. 2015. 34f. Monografia (Graduação em Língua e Literatura) - Departamento de Língua e Literatura, Universidade de Lunds, Suécia. Disponível em: <https://bit.ly/2GwZcRL>. Acesso em: 19 dez. 2018.

GARCÍA, Enrique Vercher. Un estudio comparado de partículas modales en ruso y en español. 2009. 607f. Tese (Doutorado em Filologia) - Programa de Pós-Graduação em Filologia Grega e Eslava, Universidade de Granada, Espanha. Disponível em: <http://zip.net/bxts99>. Acesso em: 18 mar. 2016.

GARCÍA, José María Buzón. La expresión de la futuridad en el español de valencia: estudio sociolingüístico. 2013. 809f. Tese (Doutorado em Filologia) - Programa de PósGraduação em Filologia, Tradução e Comunicação, Universidade de Valência, Espanha. Disponível em: <http://zip.net/bmtF3l>. Acesso em: 15 mar. 2017.

GRANDE, María Prieto; GARCÍA, Nuria Alonso. ¡Que viva España! Un enfoque comunicativo para la explicación de 'que + presente de subjuntivo' en las clases de E.L.E. 1995. Revista Centro Virtual Cervantes, ASELE, Actas VI, 1995. Disponível em: <http://zip.net/bntG7K>. Acesso em: 01 abr. 2017.

GRANVIK, Anton. Oraciones completivas de sustantivo en español y portugués: ¿infinitivo u oración finita? 2017. Revista Cuadernos de Lingüística del Colegio de México, n. 4, v. 1, p. 103-180. Disponível em: <http://bit.ly/2EZITIS>. Acesso em: 12 fev. 2018.

HENGEVELD, Kees; MACKENZIE, John Lachlan. Functional Discourse Grammar: a typologically based theory of language structure. Oxford: Oxford Linguistics, 2008.

JÍMENEZ, Santiago Sánchez. La expresión lingüistica de la finalidad en textos históricocronisticos medievales. 1999. 418f. Tese (Doutorado em Filologia) - Programa de Pós- 
Graduação em Filologia, Universidad Complutense de Madrid, Espanha. Disponível em: <encurtador.com.br/foR13>. Acesso em: 15 nov. 2017.

MARTINS, Rayane Lima; CORDELIA, Francisca. Por trás das estratégias discursivas do Papa Francisco na mensagem da quaresma de 2015. 2015. Disponível em:

<http://bit.ly/2EkmzIG>. Acesso em: 12 fev. 2018.

NEVES, Maria Helena de Moura. A modalidade. In: KOCH, I.G.V. (org.). Gramática do português falado. Vol. VI: desenvolvimentos. Campinas: Editora da UNICAMP -

FAPESP, 1996, p. 163-199.

OLBERTZ, Hella. Periphrastic expressions of non-epistemic modal necessity in Spanish: a semantic description. 2016. Disponível em: < http://zip.net/bhtFDy>. Acesso em: 27 fev. 2017.

OLIVEIRA, André Silva. Modalidade volitiva em língua espanhola nos discursos do Papa Francisco em viagem apostólica. 2017. 310f. Dissertação (Mestrado em Linguística) Programa de Pós-Graduação em Linguística. Universidade Federal do Ceará (UFC), Fortaleza. 2017. Disponível em: < http://bit.ly/2odUwqY>. Acesso em: 14 dez. 2017.

OLIVEIRA, André Silva; BATISTA, Victória Glenda Lopes; PRATA, Nadja Paulino Pessoa. Modalidade e construção discursiva em língua espanhola: a deonticidade e a volitividade em discursos de investidura. Revista Hispanista, v. 19, n. 74, 2018. Disponível em: <https://bit.ly/2T0dAU8>. Acesso em: 20 dez. 2018.

PALMER, Frank Robert. Mood and Modality. Cambridge: Cambridge University Press, 1986.

PLUCAROVÁ, Iva. La traducción de una parte de la obra de J. Tomeo: "el canto de las tortugas" con miras a verbos en la forma no personal. 2007. 53f. Monografia (Graduação em Filosofia) - Departamento de Línguas e Literaturas Românicas. Universidade de Masarykova, República Tcheca, 2007. Disponível em: <http://bit.ly/2BWwGpG>. Acesso em: 13 fev. 2018.

RODRÍGUEZ, Alba García. La expresión verbal de futuro en un serial colombiano. 2012. Revista Borealis, n. 2, v. 1, p. 1-25. Disponível em: <https://bit.ly/2KBoTyo>. Acesso em: 04 maio 2018.

RUANO, María Ángeles Sastre. Para hablar de un momento posterior a otro: la referencia al futuro. Revista Centro Virtual Cervantes, ASELE, Actas VII, 1996. Disponível em: <http://zip.net/bntG3S>. Acesso em: 30 mar. 2017.

SEDANO, Lorena Heras. Un acercamiento a la gramática de los verbos volitivos, de influencia e psicológicos. 2006. Universidad de León, Actas del XXXV Simposio Internacional de la Sociedad Española de Linguística, Filología Hispánica y Clásica, 2006. Disponível em: < http://zip.net/bctsg4> Acesso em: 16 de março de 2016.

TAPIA, Sergio Rodríguez. Equivalencias en español de los verbos modales en alemán: enfoque aplicado a la traducción. 2013. Revista Skopos, v. 3, 2013. Disponível em: <http://zip.net/bntG4f>. Acesso em: 30 mar. 2017.

TOPOR, Mihaela. Perífrasis verbales del español y rumano un estudio contrastivo. 2011. 722f. Tese (Doutorado em Linguística) - Programa de Pós-Graduação em Linguística. Universidade de Lleida, Espanha. Disponível em: < http://zip.net/bktsjX> Acesso em: 18 mar. 2016. 
Submetido em 15/05/2018 Aceito em 18/11/2018 